\title{
Milk Delivery in Tropically-Adapted Neonatal Beef Calves ${ }^{\dagger}$
}

\author{
Jarud Muller 1, Luis Prada e Silva ${ }^{2, *}$, Geoffry Fordyce ${ }^{3}$ \\ 1 Department of Agriculture and Fisheries, Charters Towers 4820, Australia; jarud.muller@daf.qld.gov.au \\ 2 Queensland Alliance for Agriculture and Food Innovation, Centre for Animal Science, The University of \\ Queensland, Gatton 4343, Australia \\ 3 Queensland Alliance for Agriculture and Food Innovation, Centre for Animal Science, The University of \\ Queensland, Charters Towers 4820, Australia; g.fordyce@uq.edu.au \\ * Correspondence: 1.pradaesilva@uq.edu.au \\ † Presented at the Third International Tropical Agriculture Conference (TROPAG 2019), Brisbane, Australia, \\ 11-13 November 2019.
}

Published: 16 March 2020

\begin{abstract}
Across beef breeding herds of northern Australia, poor pre-partum nutrition of cows is consistently associated with increased calf wastage between confirmed pregnancy and weaning. With key nutrients at play (especially energy, protein, phosphorus and water) also being associated with milk yields, a specific problem mediating calf mortality is likely to be low milk production and delivery during the highest-mortality-risk period that is the first week after birth. Recent research demonstrated that milk-deprived newborn calves die of dehydration within 1-3 days. Newborn Brahman and tropical composite calves across three grazing herds $(n=75)$ and two penned herds $(\mathrm{n}=106)$ were investigated. Calf milk uptake during the first 1-2 days of life was measured by plasma immunoglobulin (IgG) levels and overall milk uptake and health during the first two weeks of life was measured by growth rate from birth. Grazing calves with average IgG levels of 2247, 2508 , and $2656 \mathrm{mg} / 100 \mathrm{~mL}$ had respective average growth rates of $0.5,1.0$, and $1.4 \mathrm{~kg} / \mathrm{d}$. Penned calves with average IgG levels of 2064, 2498 and $2504 \mathrm{mg} / 100 \mathrm{~mL}$ had respective average growth rates of $0.6,1.0$, and $1.4 \mathrm{~kg} / \mathrm{d}$. The association between calf immunoglobulin uptake and initial growth demonstrates individual variation between tropical beef calves for early milk uptake and that risk factors limiting milk delivery in the first days of life would place calves at greater risk of poor health and mortality.
\end{abstract}

Keywords: calf; survival; neonatal; milk

Author Contributions: Work was initiated as Master of Philosophy project, with author one as the student and author two as principal advisor. This subsequently led to a study led by author two, with authors one and three contributing. Data from both projects are included in this study.

Funding: The grazing study was funded by Meat and Livestock Australia Science and Innovation Award for young people; the pen study was funded by the Australian Centre for International Research.

Acknowledgments: In-kind support was provided by the Queensland Department of Agriculture and Fisheries and the Queensland Alliance for Agriculture and Food Innovation.

Conflicts of Interest: The authors declare no conflict of interest.

(C) 2020 by the authors. Licensee MDPI, Basel, Switzerland. This article is an open access article distributed under the terms and conditions of the Creative Commons Attribution (CC BY) license (http://creativecommons.org/licenses/by/4.0/). 